\title{
Farmland Landscape Pattern Change in Changping District of Beijing in Recent Ten Years
}

\author{
Wang Zhiying ${ }^{1}$, Zhang Defeng ${ }^{1}$, Liu Yun ${ }^{1} *$, Li Chunlei ${ }^{2 *}$ \\ 1.The Beijing key laboratory of new technology in Agricultural application, Beijing University of Agriculture, Beijing \\ 102206, China ; 2.Institute of forest ecology environment and protection, Chinese Academy of Forestry, 100091, China \\ * Corresponding author: Liu Yun, E-mail:housqly@ 126.com; Li Chunlei, E-mail: lclxj@ sina.com
}

\begin{abstract}
With the development of economy in recent years, Beijing's urbanization is rapid expansion and it has great influence on suburban farmland. This article analyzed the variation of the cultivated land and landscape pattern during the period of 1998-2009, based on TM images data in 1998 and 2009, land use map and administration planning map of Beijing in 2005, by the RS, GIS and Fragstas software platform. The results showed as follows: That the cultivated land in Changping District of Beijing had converted mainly into construction land about 10818.36 ha with the percentage of $\mathbf{4 8 . 4 5}$,but also forest land converted into cultivated land about $\mathbf{7 7 4 0 . 9 9}$ ha. The indexes of landscape pattern had different change trend. The CA decreased about $13.8 \%$, however, NP and Pd increased $75.7 \%$, which meant that the fragmentation degree of landscape had increased; the AI and CONTAG of mosaic indexes had decreased $5.9 \%$ and $\mathbf{1 1 . 9 \%}$, and also the same declined trend for the PLAND and LPI of dominance indexes with $13.8 \%, 72.7 \%$ respectively, but the increased $16.2 \%$ for the Shannon diversity index, which meant that the heterogeneity intensity of landscape had increased, and connectivity decreased; the LSI and ED had the same increased trend of $36.1 \%$ and $26.3 \%$ respectively in the past 10 years, which meant that the boundary of patches had more complex characteristic.
\end{abstract}

Keywords- cultivated land; landscape pattern index; transition matrix; suburban area of Beijing

\section{INTRODUCTION}

As public resource products, the quantity and quality of cultivated land has close relationship with the country's food security, and it plays a significant role in maintenance the national security and social stability [1]. China has the most stringent farmland protection policy in the world. It has become the general consensus of the whole country of sticking to the "red line" for 18 million $\mathrm{mu}$ of cultivated land [2]. Conversion of arable land has a more profound impact to the quality of cultivated land in the current system of balance arable land [3-4].

After China reform and opening to the world, with the rapid development of society and economy, as the political and cultural center, Beijing has undergone enormous changes in the past 20 years. With the rapid development of urbanization process, Beijing is mainly a lot of land occupied by construction land [5], such as factories, shops, residential and so on.

As the main elements of land-use landscape [6], the spatio-temporal pattern of cultivated land change plays an important role on spatial pattern of land use. Maintaining and preserving the stability of the landscape of cultivated land is the most urgent problem to be solved in order to plan land use and protect farmland [3]. Urbanization has basically been completed in urban Beijing, and residual arable land is scarce [7]. Consequently, it is strategic significance for the research on farmland landscape in the suburb area of Beijing, and will also provide reference basis for the sustainable development of suburb area of Beijing. This paper studies the changes of farmland landscape in Changping district located in northwest of the city center of Beijing.

\section{BACKGROUND OF RESEARCH LOCATION}

\section{Changping district is $\left(40^{\circ} 2^{\prime} 18^{\prime \prime} \mathrm{N} \sim\right.$} $\left.40^{\circ} 23^{\prime} 13^{\prime \prime} \mathrm{N} ; 115^{\circ} 50^{\prime} 17^{\prime \prime} \mathrm{E} \sim 116^{\circ} 29^{\prime} 49^{\prime \prime} \mathrm{E}\right)$ located in the northwest of Beijing center, and is one of the suburban districts and counties in Beijing (see Figure 1). Its total area is $1352 \mathrm{~km}^{2}$, and the size of arable land is 28 million mu. Changping is situated on the combined area of floodplain of Wenyu River and offshoot of Yanshan and Taihang mountains. Terrain is from high in northwest to low in southeast. Two third of total area is mountain or mid-mountain. The elevation of mountain area is from $800 \mathrm{~m}$ to $1,000 \mathrm{~m}$, and plain area is from $30 \mathrm{~m}$ to $100 \mathrm{~m}$. The main rivers belong to Wenyu River. Changping is characterized by warm temperate, semi-humid continental monsoon climate. The mean annual sunshine is $2684 \mathrm{~h}$. The mean annual temperature is $11.8^{\circ} \mathrm{C}$, and mean annual precipitation is $550.3 \mathrm{~mm}$.

\section{DATA AND METHODS}

The source datum are consist of two periods of LANDSAT-5 TM images in 1998 and 2009 with 30 meter spatial resolution, and DEM data from the huttle Radar Topography Mission ( SRTM) of Global land cover facility (GLCF) with 90 meter of spatial resolution.

On ERDAS and ARCGIS software, pre-processing of TM images at two periods, geometric correction, polygon 
subset were done, image enhancement, and then it applied supervised classification and unsupervised classification

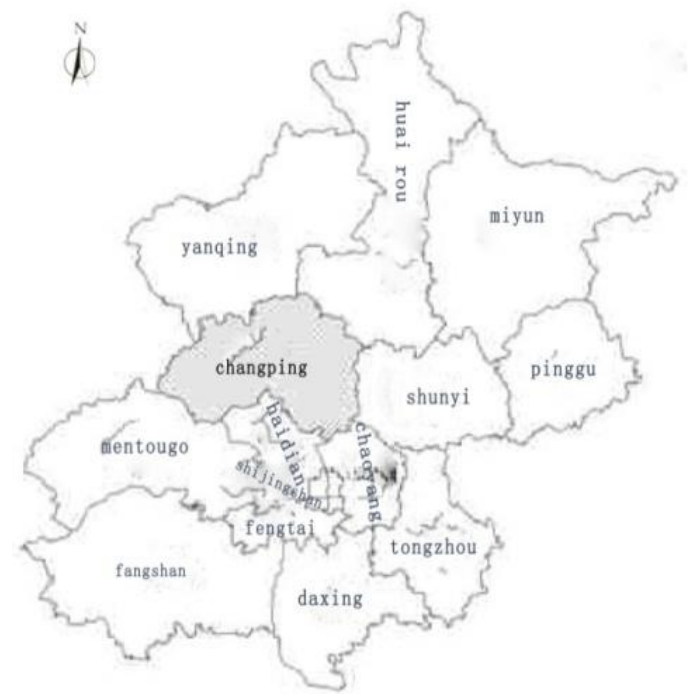

Figure 1 The administrative map of Beijing

to obtain polygon maps of land use. The accuracy of overall classification can reach $98.72 \%$. Then extracting of thematic data based on human-machine interactive interpretation under the support of ARCGIS. Combine with the characteristics of on-spot investigation in Changping, It was classified into 6 landscape types and 18 patch types. In this study, landscape patches were classified into: cultivated land, forested land, construction land, water, grassland and unused land. Then it calculated the transfer matrix of land use and landscape pattern index under the support of ERDAS and FRAGSTATS ( version3.3. The transfer matrix of land use and landscape pattern index were seen in Table 1 . It should be pointed out that due to measurement difficulties, some linear features were included in the landscape patch, such as roads and ditches [8]. The flowchart of this research was seen in figure 2 .

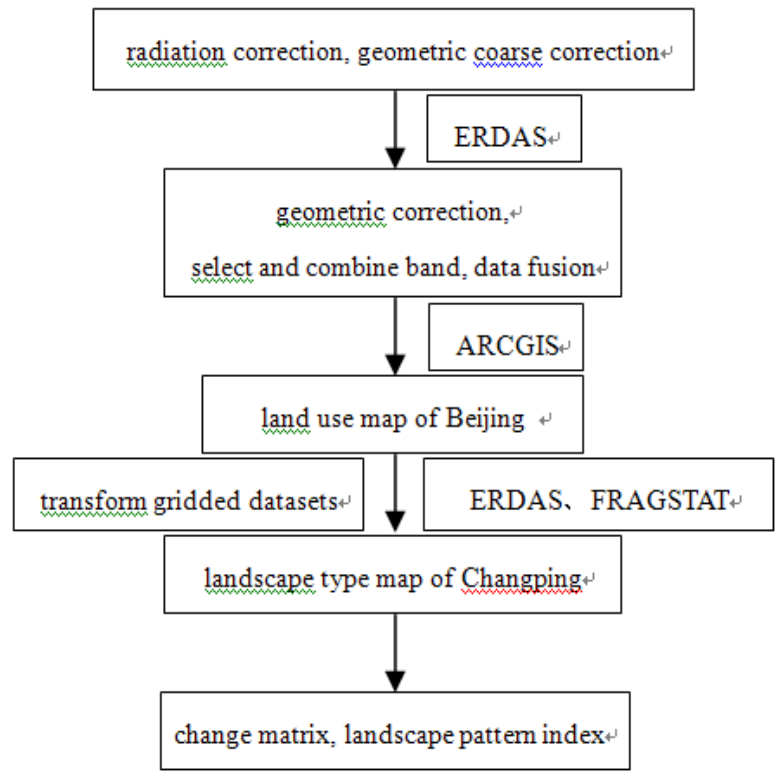

Figure 2 The flowthart of this research

\section{RESULTS AND DISCUSSION}

\section{A. The trend of landscape land use changes}

The Figure 3 showed the changes of landscape land use in Changping area from 1998 to 2009. We could see that cultivated land and it's quantity were sharply reduced, and that it was broken distribution. At the same time, construction land was increased. It is account for the sharply urbanization in Changping area from 1998 to 2009.

Table 1 Landscape pattern index

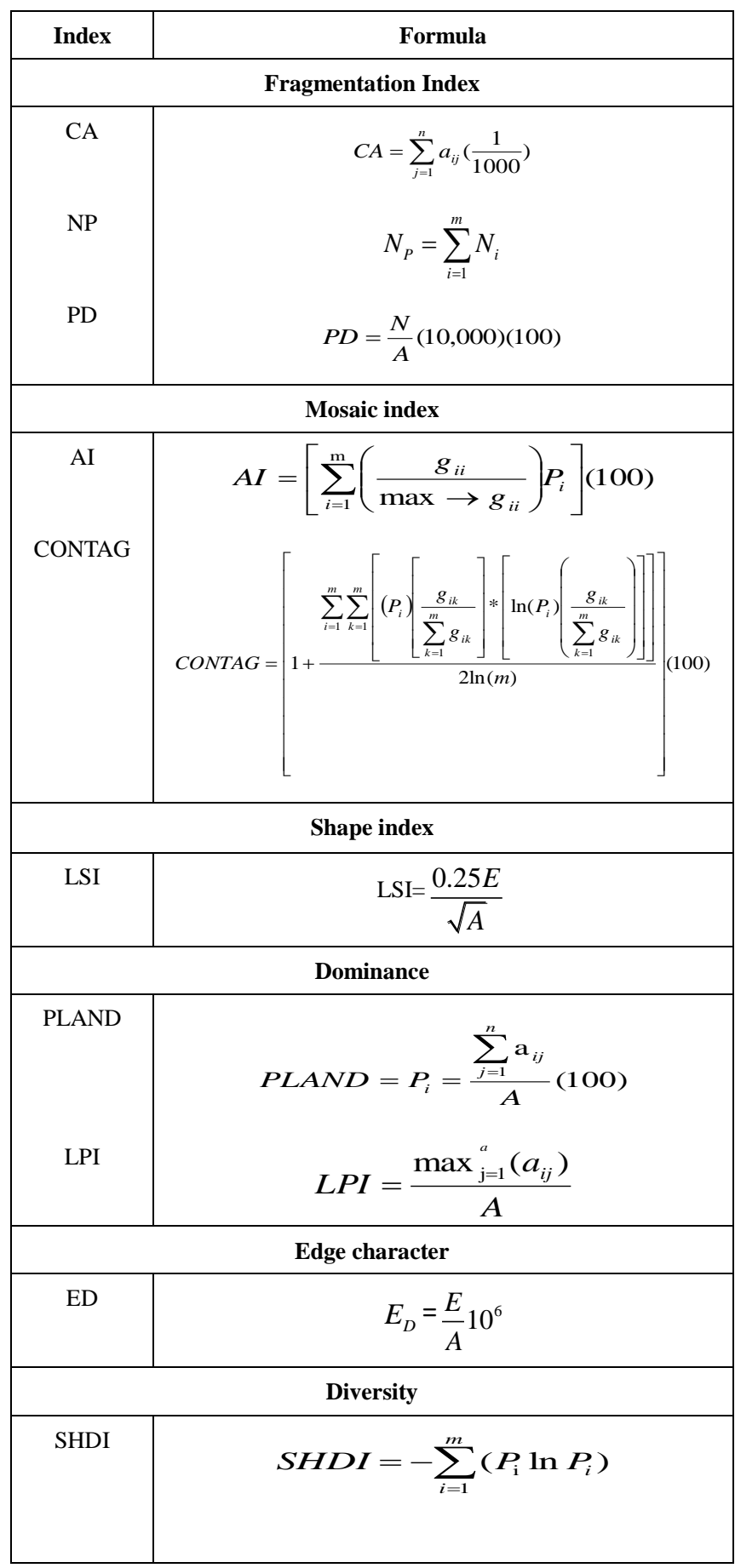




\section{B. Land use change matrices}

The transition matrices (Table 2 and 3 ) highlighted the dominant dynamic events during the study period. It could be seen that cultivated land converted to forest, construction land, water, grassland and unused land from 1998 to 2009. The transition areas were $2674.62 \mathrm{hm}^{2}$, $10818.36 \mathrm{hm}^{2}, 196.65 \mathrm{hm}^{2}, 1691.73 \mathrm{hm}^{2}$ and $128.43 \mathrm{hm}^{2}$, respectively, corresponding transferring rates were $11.98 \%$, $48.45 \%, 0.88 \%, 7.58 \%, 0.58 \%$. The most prominent land use change has been happened from cultivated land to construction land. It is resulted from rapidly urbanization in Changping district.

In addition, forest land, construction land, water, grassland and unused land also shifted to cultivated land. The transition areas were $7740.99 \mathrm{hm}^{2}, 3838.32 \mathrm{hm}^{2}$, $940.32 \mathrm{hm}^{2}, 117.72 \mathrm{hm}^{2}$ and $78.21 \mathrm{hm}^{2}$, respectively, corresponding transferring rates were $8.95 \%, 20.41 \%$, $26.49 \%, 0.21 \%$ and $49.57 \%$. The unused land, water and forest land is more convert to cultivated land. This is inseparable from the sand control project.

\section{Landscape pattern index}

The table4 showed changes of landscape pattern index of Changping from 1998 to 2009 . We could see that CA of cultivated land decreased from $22858.83 \mathrm{~m}^{2}$ to 19698.12 $\mathrm{m}^{2}$, the NP increased from 931 to 1636 , the PD also increased from 0.4165 to 0.7319 , which indicated the landscape fragmentation of cultivated land had been increased. AI and CONTAG were decreased from $88.8551 \%$ and $62.6052 \%$ in 1998 to $83.5801 \%$ and $55.1412 \%$ in 2009 , and respectively decreased by $5.9 \%$ and $11.9 \%$. It indicated that common boundary of cultivated land were reduced, and that polymerization degree and connection degree of patches were reduced. LSI increased from 57.0526 to 77.6261during 1998-2009, which showed that the shape of landscape patch in Changping is more and more irregular and the degree of shape complicated increased. PLAND and LPI were decreased from $10.2271 \%$ and $2.0468 \%$ in 1998 to $8.8130 \%$ and $0.5585 \%$ in 2009 , respectively. It's the result of human activities on farmland landscape, which made the large area of cultivated land patches rapidly decreased and the trend to be more human planning. ED was increased from 15.4377 in 1998 to 19.5044 in 2009, which reflected the degree of patch fragmentation and spatial heterogeneity increased. SHDI increased from 1.2686 to 1.4747 , reflected the land use more diversification and the patch types increased or the trend of various patch types in the landscape were balanced distribution for recent 10 years.

\section{CONCLUSION}

The area of cultivated land in Changping district has been lost during 1998-2009. It mainly changed into construction land. The landscape pattern of cultivated land had tend to increasing fragmentation, and decreasing mosaic degree, and its spatial connectivity, spread degree, and dominance were reduced. The shape of patch was more complicated, and space heterogeneity was greater, and the overall landscape pattern was diversity. Certainly, there are still inadequacies in this article. With only two LANDSAT TM images in 1998 and 2009, and the interpreting error of water types based on supervised classification and so on

\section{ACKNOWLEDGMENT}

Partial funding for this research was provided by National Natural Science Foundation of China (No. 40871232 \& 40501029), Beijing youth backbone teachers project" of Beijing higher education school education plan in 2011 (No. PHR201108286), and the Project of construction of innovative teams and teacher career development for universities and colleges under Beijing Municipality, and the creative group project from Prof. Zhao Jianzhuang. Otherwise, Liu Yun and Li Chunlei have the same contribution for the article, and they are the corresponding authors.

\section{REFERENCES}

[1] J. K. Zhang, F. R. Zhang, L. Zhang, et al., "Comparison between the potential grain productivity and the actual grain yield of cultivated lands in Mainland China", Scientia Agricultura Sinica, 2006, Vol.39(11), pp2278-2285.

[2] G. H. Jiang, T. T. Zhao, Z. Q. Duan, et al., "Cultivated land quality change and its future trend modeling in Beijing mountainous area", Transactions of the Chinese Society of Agricultural Engineering, 2010, Vol.26(10), pp304-311.

[3] C. Y. He, P. J. Shi, J. Chen. "A study on land use/cover change in Beijing area”, Geographical Research, 2001, Vol.20(6), pp679-686.

[4] H. P. Zhao, F. R. Zhang. "Analysis of agricultural landscape and the zoning layout of agricultural function in Beijing", Transactions of the Chinese Society of Agricultural Engineering, 2008, Vol.24, pp78-84.

[5] W. Li, L. Q. Chen, T. J. Zhou, “The countermeasures and influences on cultivated land protection of urbanization development in China”, Guangdong Land Science, 2010, Vol.9(6), pp14-18.

[6] X. W. Li, P. Lin, D, J, Zhu, "Piedmont cultivated land by using landscape dynamic analysis and quality evaluation", China Land Science, 2000, Vol.14(3), pp40-47.

[7] P. L. Wu, Q. Lu, G. X. Wang, "Study on cultivated land loss and its driving forces in Beijing 1981-2001”, China Population, Resources and Environment, 2004, Vol.14(3), pp109-115.

[8] Y. J. Sun, Q. X. Wang, Z. H. Lu, "Effects of urbanization on landscape pattern of Beijing", Chinese Journal of Applied Ecology, 2005, Vol.16(7), pp1366-1369. 


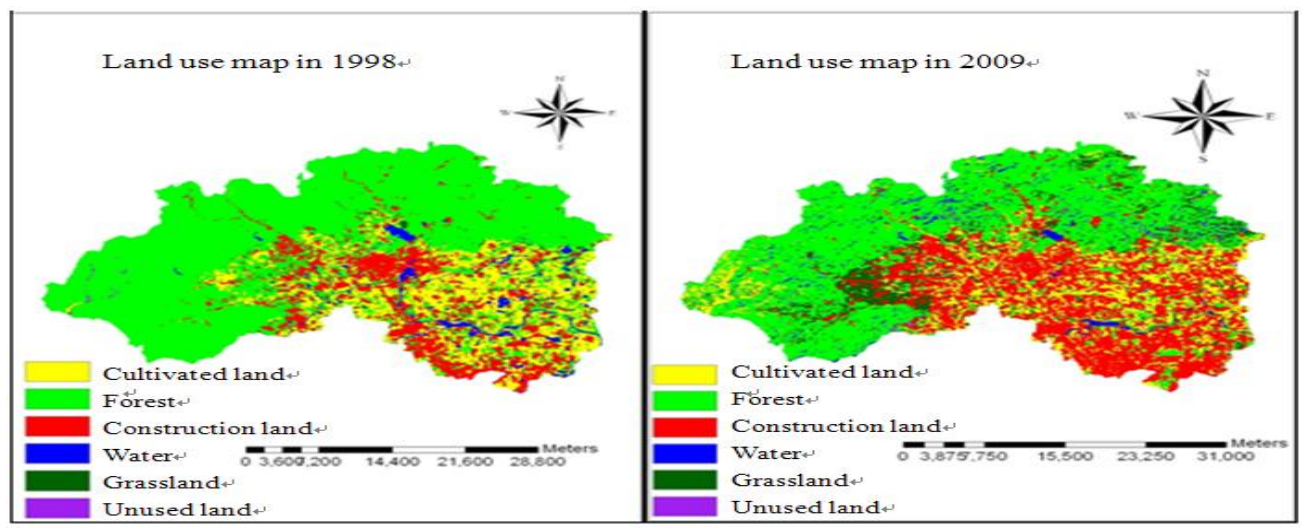

Figure3 Land use map of Changping District in Beijing

Table 2 Transition matrix of and use in 1998 and 2009(unit: $\mathrm{hm}^{2}$ )

\begin{tabular}{|c|c|c|c|c|c|c|c|}
\hline \multirow{2}{*}{1998} & \multicolumn{6}{|c|}{2009} & \multirow{2}{*}{ Total } \\
\hline & Cul & For & Con & Wat & Gra & Unl & \\
\hline $\mathrm{Cul}$ & 6819.57 & 2674.62 & 10818.36 & 196.65 & 1691.73 & 128.43 & 22329.36 \\
\hline For & 7740.99 & 56092.23 & 10170.27 & 2708.01 & 8924.31 & 882.72 & 86518.53 \\
\hline Con & 3838.32 & 1584.09 & 12526.29 & 110.52 & 725.58 & 23.49 & 18808.29 \\
\hline Wat & 940.32 & 489.6 & 1562.22 & 404.1 & 146.16 & 7.38 & 3549.78 \\
\hline Gra & 117.72 & 259.29 & 204.48 & 2.34 & 122.31 & 7.47 & 713.61 \\
\hline Unl & 78.21 & 59.04 & 10.62 & 4.05 & 5.67 & 0.18 & 157.77 \\
\hline Total & 19535.13 & 61158.87 & 35292.24 & 3425.67 & 11615.76 & 1049.67 & 132077.34 \\
\hline
\end{tabular}

Note: Cul=Cultivated land; For=Forest; Con=Construction land; Wat=Water; Gra=Grassland; Unl=Unused land.

Table 3 The transfer percentage of land use (unit: \%)

\begin{tabular}{|c|c|c|c|c|c|c|}
\hline \multirow{2}{*}{1998} & \multicolumn{6}{|c|}{2009} \\
\hline & $\mathrm{Cul}$ & For & Con & Wat & Gra & Unl \\
\hline Cul & 30.54 & 11.98 & 48.45 & 0.88 & 7.58 & 0.58 \\
\hline For & 8.95 & 64.93 & 11.76 & 3.13 & 10.31 & 1.02 \\
\hline Con & 20.41 & 8.42 & 66.6 & 0.59 & 3.86 & 0.12 \\
\hline Wat & 26.49 & 13.79 & 44.01 & 11.38 & 4.12 & 0.21 \\
\hline Gra & 16.5 & 36.33 & 28.65 & 0.33 & 17.14 & 1.05 \\
\hline Unl & 49.57 & 37.42 & 6.73 & 2.57 & 3.59 & 0.02 \\
\hline
\end{tabular}

Note: Cul=Cultivated land; For=Forest; Con=Construction land; Wat=Water; Gra=Grassland; Unl=Unused land.

Table 4 Landscape pattern indexes of cultivated land between 1998 and 2009

\begin{tabular}{|c|c|c|c|c|}
\hline Index type & Index & 1998 & 2009 & Change rate $(\%)$ \\
\hline \multirow{3}{*}{ Fragmentation Index } & Classes area (CA) & 22858.83 & 19698.12 & -13.8 \\
\hline & Numbers of patch (NP) & 931 & 1636 & +75.7 \\
\hline & Patch density (PD) & 0.4165 & 0.7319 & +75.7 \\
\hline \multirow{2}{*}{ Mosaic index } & Assimilate index (AI) & 88.8551 & 83.5801 & -5.9 \\
\hline & Cotangent index (CONTAG) & 62.6052 & 55.1412 & -11.9 \\
\hline Shape index & Landscape shape index (LSI) & 57.0526 & 77.6261 & +36.1 \\
\hline \multirow{2}{*}{ Dominance } & Percentage of landscape (PLAND) & 10.2271 & 8.813 & -13.8 \\
\hline & Largest patch index (LPI) & 2.0468 & 0.5585 & -72.7 \\
\hline Edge character & Edge density (ED) & 15.4377 & 19.5044 & +26.3 \\
\hline Diversity & Shannon diversity index(SHDI) & 1.2686 & 1.4747 & +16.2 \\
\hline
\end{tabular}

